\title{
Semiotics of Biosignatures
}

\author{
David Dunér
}

\begin{abstract}
Professor of History of Science and Ideas, Lund University. History of Science and Ideas, Lund University, Lux, Box 192, 22100 Lund, Sweden. Cognitive Semiotics, Lund University, Sweden. The Pufendorf Institute for Advanced Studies, Lund University, Sweden. E-mail: David.Duner@kultur.lu.se
\end{abstract}

\begin{abstract}
This article examines the interpretation of biosignatures, the signs of life that could be detected in outer space. In astrobiology biosignatures could be of various kinds, fossils, molecules, traces, artefacts, structures, electromagnetic waves, etc. The purpose of this article is to bring some semiotic order in this seemingly chaotic variation of signs. It turns out that the semiotic function of these signs varies a lot, and each has their own epistemological problems and semiotic peculiarities. The article put forward a semiotics of biosignatures, i.e., how we, as interpreters, establish connections between things, between the expression (the biosignature) and the content (the living organism) in various forms of semiosis, as icons, indices, and symbols of life. In all, it is about how we get access to the world, and how we interpret and understand it, for achieving a wellgrounded knowledge about the living Universe.
\end{abstract}

Keywords: astrobiology, biosignatures, cognitive semiotics, icon, index, life, semiosis, symbol

"...all this universe is perfused with signs, if it is not composed exclusively of signs." C. S. Peirce, "The Basis of Pragmaticism in the Normative Sciences" $(1906 ; 1998,394)$ 


\section{Introduction}

In the quest for life in Universe, the most likely scenario is that we one day might find signs of life, biosignatures, that indicate certain biochemical processes that could have their origin in extraterrestrial biological activity. This is what we can hope for, insomuch as we will not in the foreseeable future find ways of exploring, in situ, foreign worlds around other stars. On one hand we might come across observable and verifiable phenomena that we call "biosignatures," and on the other, we infer the existence of certain unknown instances of known biochemical processes that we call "life" that we suppose are the causes of the former. In other words, we make connections between the expression (the biosignature) and the content (the living organism). The ones who make this connection are we human beings, with our inventive minds that are a result of a particular bio-cultural coevolution of human cognition, of our species, here on Earth (Dunér and Sonesson 2016; Dunér 2016). This is what semiotics of biosignatures is all about.

Biosignatures concern various things, and refer to chemical substances (elements, molecules, etc.), but also physical features (structures, shapes, morphology, etc.), and physical phenomena (electromagnetic radiation, light, temperature, etc.). They can vary in scale from atomic to planetary magnitude, or perhaps even larger. They can be searched for both by in situ investigations and through remote indirect sensing, on our nearest planets and moons as well as in other solar systems. These signatures are meant to be evidence for either living life or dead life, present or past life, distinctive from an abiogenic background. In this article, I will put forward a semiotics of biosignatures, how we, as interpreters, establish connections between things, between the expression and the content in various forms of semiosis, as icons, indices, and symbols of life. It is about how we get access to the world, and how we interpret and understand it, for achieving a well-grounded knowledge about the living Universe.

\section{Astrobiosemiotics}

The semiotics of biosignatures is about the meaning-making processes of the human mind and its ability to make meaningful connections between things. The problem of biosignatures is very much a semiotic problem: how meaning can be discovered, invented, deciphered, and interpreted. One might say that the science of astrobiology "invents" connections between the signifier and the signified, expression and object, "signs of life" and "life." The first problem that arises in a situation of interpreting a biosignature is realising that it really is a sign at all. Some regularity and order, or finding a repetition in the pattern is not enough. The sign should be recognized as such by the interpreter, i.e., that it contains an expression that refers to a content, leading to an interpretive process by the interpreter. In other words, the interpreter needs to identify the physical phenomenon as containing semiotic meaning, something that can be a sign of life, a biosignature, that has a particular meaning by referring to its content 
"life." In our everyday lives as well as in well-established science, the expression of a phenomenon can easily be connected to its content. Seeing the footprints of an animal, we can infer - based on previous knowledge - what kind of animal it is, its weight and its direction. However, this semiotic confidence becomes much more uncertain when we turn to biosignatures of unknown forms of life. We are compelled to a number of assumptions that underlie the connection we try to establish between the expression and the content. Our assumptions might be mistaken, which leads to wrong interpretations, or even worse, we fail to make any assumptions at all, in other words, the phenomenon encountered, "the signature," would not be recognized as a meaningful sign whatsoever. Even though we have good reasons to believe that the connection we infer between the expression and the content, between the biosignature and the living organism, is scientifically correct, we need to rule out other explanations of the signrelation. The "biosignature" might not be a true biosignature at all, but instead is caused by an unknown or known abiotic process.

Semiotics could help us to bring some order among the various kinds of biosignatures and unearth the underlying signrelations and the epistemological problems that follow with them. A certain sub-field of research, biosemiotics, has focused on the production and interpretation of signs in the biological realm (Wheeler 2006; Hoffmeyer and Favareau 2008; Romanini and Fernández 2014). Cognitive semiotics, on the other hand, studies the meaning-making structured by the use of different sign vehicles, and the properties of meaningful interactions with the surrounding environment, both with the physical and the social environment (Sonesson 2007, 2009; Zlatev 2012, 2015; Dunér and Sonesson 2016). Following attempt to uncover the meaning-making strategies in the search for biosignatures takes its departure from cognitive semiotics and related fields of research. Semiotic approaches towards the semiosis of biosignatures are lacking, however there are some few examples of studies that put forward the relevance of semiotics for the construction and decoding of interstellar messages (Vakoch 1998a, 1998b; Dunér 2011; Sonesson 2013; Saint-Gelais 2014).

As the study of meaning-making, semiotics concerns signs, which can be said to be something that we interpret as having meaning. According to Peirce, "A sign, or representamen, is something that stands to somebody for something in some respect or capacity" (Peirce 1932, 135; Saint-Gelais 2014). The sign, as expression, stands for something, its object. The sign does not include its meaning, rather the meaning is attributed through elaboration of an interpreter. So for something to be meaningful, an interpreter is needed, a human being (or other meaning-making creatures) who endows the sign a meaning. A physical phenomenon is meaningless so far as there is no one to recognize it as meaningful. Phenomena that we call biosignatures become meaningful phenomena, when we interpret them as containing a meaning by making a connection between the expression and the object, in other words, between the "biosignature" and "the living organism." The signs are the way we make sense of the world, to approach it, to get access to it and differentiate things from each other. Correspondingly, the 
biosignatures we detect are one way among many other ways of making sense of the data we receive from outer space. And these biosignatures exist so far as we find them meaningful. In that perspective, the biosignatures are not solely "out there," instead, they are to a great extent in our minds, in the interaction between our minds and the outer world. It is in our meaning-making practices the "biosignatures" become biosignatures. In that sense, when the astrobiologist is interpreting biosignatures, he or she is involved in a meaning producing semiosis. This semiosis is triadic, it contains expression, object, and interpreter - which in our case respond to "biosignature," "life," and "astrobiologist." Depending on how the interpreter makes or interprets the connection between the expression and the object, we have basically three types of signrelations, icon, index, and symbol. But, let us return to these signrelations in more detail later on. For now, it is enough to conclude that the astrobiologist searching for biosignatures is a sort of semiotician, an astrobio-semiotician, trying to establish connections between expressions and objects in the Universe. Semiotics of biosignatures concerns qualities and categories, as well as the search for rules and regularities within such a nomothetic science as astrobiology concerned with generalities. More generally, semiotics of biosignatures concerns the meaning-making processes of astrobiology.

Finding the connection between expression and content are actually mental, in the mind of the interpreter. The search for biosignatures is based on the human endeavour of connecting things with each other, and of selecting the right elements for the connection among a wider range of possible elements. We ask ourselves, what are the meaningful properties of the information we gather through spectrometers, radio or optical telescopes, etc.? Which signatures (phenomena) have meaning and which are just meaningless noises? Hence, we are looking for the meaningful signs among a chaotic "noise" of data, the "biosignatures" that clearly "says" that they are signs of "life." The signifier is directly given, but the signified is only indirectly present, through the link with the signifier. "Life" (the signified) that we are searching for is just indirectly reachable for us, and we have to content ourselves with the only thing that is directly given, the biosignature (the signifier). As interpreters, we determine the relation between the signifier and the signified by picking out those elements we assume to be relevant. The challenge of the astrobiologist is to pick the right elements (properties) of the signifier. For example, when examining a Martian rock, we need to pick out those elements (shapes, molecules, etc.) that direct us to the signified, the living organism. And we need a reasonable explanation of the link between the signifier and the signified. Why, and how come, is this particular gas a result of a certain metabolism of a living organism? In what way is this shape a remnant of the morphology of a living organism? We need to know the physical processes that let us link the signifier with the signified.

In the following three sections, I will show that "biosignatures" is a very diverse category, not only in respect to its immense variety of expressions, but also in semiotic sense. It shows a great variation in signrelations that each has its particular 
epistemological problems. To begin with, in astrobiology the concept of "biosignature" is not completely unambiguous. The concept of "biomarker" is sometimes used interchangeably with "biosignature," but often restricted to refer to "an organic molecule whose origin can be directly related to an organic component of life" (Horneck et al. 2016, 227), or organic compounds characteristic of certain organisms, for example hopanoids in cell membranes of cyanobacteria. Biosignature, instead, refers to a broader range of signatures of life: morphological, geochemical, and organic - a diverse and ambiguous category of signatures, related to either living organisms or fossilized remains. Biosignatures could be studied in situ, being of physico-chemical, geological, morphological, and mineralogical nature. Or they can be detected by remote methods, such as atmospheric spectroscopy, chemical disequilibrium, isotope ratios, etc. (Hegde et al. 2015). Physical microbial structures, stromatolites, mud mounds, atmospheric gases, etc., could be biosignatures, varying in scale from prebiotic molecular features to entire planets, referring to both life as we know it and weird life, past and present life.

The following is a first attempt to bring some semiotic order in this chaotic variation of signs. Based on Peirce three signrelations - icon, index, and symbol - one could at least reveal some peculiarities of the semiosis of biosignatures. The meaning of the relation between expression and content, that the interpreter experiences, is based on either similarity (iconicity), proximity (indexicality), or habits, rules, or conventions (symbolicity). An icon is when the expression shares some similarity with the object. An index is when the expression has some contiguity with the object. And finally, a symbol is when the connection between expression and object is just a mere convention. Thus I put forward three kinds of biosignatures in semiotic sense: bioicons, bioindices, and biosymbols. However, in many cases a sign could be a combination index, icon, and/or symbol, also as we will see in the case of biosignatures.

\section{Bioicons}

Aristotle once noticed similarities between certain seashell-shaped structures found in rocks and those that washed ashore on the beach. Are there a connection between the petrified seashells and the living ones? And how come? In the beginning of the eleventh century, the Persian polymath Ibn-Sīnā (Avicenna) put forward the theory of petrifying

fluids as an explanation of the petrification. Through the ages, the question was debated, if these figure stones that resembled living organisms actually were fossilized seashells or just sports of nature, lusus naturae, if they grow in the bedrock or were traces of once living animals exterminated by the flood. In 1665, the Danish anatomist and geologist Nicolaus Steno found shark teeth in the Tuscan mountains, suggesting that where it is now high mountains, it had once been a sea (Cutler 2003). Other findings, however, seemed to have no counterparts in the living species. By the end of the eighteenth century, the French palaeontologist Georges Cuvier began realizing that they actually were remnants of extinct species. 
The idea of fossils was also combined with the idea of extraterrestrial life. If meteorites were coming from outer space, as it was realized in the early nineteenth century, rather than being ejecta from volcanoes, these could be studied by chemical and geological methods. These meteorites from other worlds might contain evidence of extraterrestrial life, if not alive, in fossilized form. The analytical chemist Jöns Jacob Berzelius (1834) discovered that meteorites contained organic materials (hydrocarbons). He examined meteors from a meteor shower in November 1833, made a chemical analysis of a carbonaceous chondrite that had fallen in 1806, in Alais (Alès), France, but could not tell if it contained carboniferous of extraterrestrial origin (Crowe 1986). In the 1870s it was consensus that some meteorites contained organic materials, but no convincing evidence had been found that they contained extraterrestrial life forms. With Berzelius and others the idea of panspermia, that seed-bearing meteoric stones are moving around in outer space, became an increasingly plausible area of research, ending up in the physical chemist Svante Arrhenius's (1907) more elaborated panspermia hypothesis. And still, the hypothesis has not been completely ruled out. Current research has shown that microbial life could indeed travel between planets and survive in space (Horneck et al. 2010).

A theme in the history of palaeontology is the question of how to distinguish real remnants of living organisms from structures that just mimic living forms, to distinguish fossils from pseudofossils. These inorganic pseudofossils can be mistaken for fossils, for example branch-like structures like manganese dendrites in limestone, kidney ore, moss agates resembling moss leaves and other patterns in rock that arise through geological, not biological processes. This is still a challenge in the quest for microfossils for tracing the early history of life on Earth or in order to find fossilized life in Martian rocks. A famous example is the announcement in 1996, that fossilized life had been discovered in the Martian meteorite ALH84001 (McKay et al. 1996). Viewed under an electron microscope, certain tube-like structures in the meteorite resembled fossilized bacteria. It was a premature claim; abiological processes could in fact create these structures (Westall et al. 1998). This calls for new samples when claiming evidence for fossilized life in rocks on Mars or beyond. A second lot is needed to confirm or refute previous hypotheses based on the first batch of samples, or to continue the search.

Biosignatures in the form fossils are distinctly another thing than remote sensing of habitable atmospheres, not because how they are found, in situ, but in its signrelation. Biosignatures that share a similarity with living organisms, for example fossils, are in my terminology bioicons, i.e., a signrelation based on similarity, where the expression shares some of the object's properties. The similarity between properties is perceived on the background of other dissimilar properties. The most obvious examples of bioicons are body fossils, the imprints of the hard parts of animals and plants, where the imprints of skeletons or foliage let us, based on morphologic similarity, establish a link between the fossilized structure and the living thing. The very complexity of the expression (the fossil) directs us to the conclusion, based on the supposition that such a complexity cannot be the result of any known abiotic process. Microscopic fossils, 
microfossils, though, are more challenging. All life as we know it share the characteristics of having internal volumes isolated from the surrounding environment by a cell membrane. Based on this shared morphology, one could search for cellular structures. Well-preserved fossil cells can be identical in size, shape, and structure with living single-cell organisms. Their structures, that show less complexity, make it however more challenging to distinguish a biotic structure from an abiotic. On Earth, the Apex chert from Western Australia, dated at $~ 3.5 \mathrm{Ga}$, has been claimed either to be fossilized cells of filamentous bacteria or just a result of an abiotic process (Schopf 1993; Brasier et al. 2005). To be a true biosignature, it is not enough to notice a similarity between the expression and the object. We also need an explanation for how a living organism can become a fossil (a bioicon). If we find something that reminds us of a living thing, a microbe, a cell or that like, we need also a theory that links the living organism with the biosignature, establishing a physical correlation between the bioicon and the thing it signifies. Plenty of performed experimental fossilisation studies give us the right arguments to make this connection. Further more, fossils are not enough if we want to get a complete understanding of the life it refers to; they do not give us complete information of the biochemical nature of the living organism.

Bioicons are not just of visual nature, a similarity based on morphology or structure, they could exist in any sense modality. Based on chemical analyses, the researcher sees similarities between the expression and the content, not because of structural similarity, but because they share some chemical properties. In the case of chemical biosignatures, some are bioicons in that sense that the discovered biosignature has a chemical similarity or shared characteristics with the living organism, for example complex biological macromolecules, like carbohydrates, lipids, proteins, and nucleic acids (RNA and DNA). Most common biomolecules, however, usually modify and degrade, and the products (also called "molecular fossils") of this chemical breakdown (the diagenesis) have instead an indexical relation to the bioiconic biological macromolecules. For example the 2-methyl hopanes that are known to be the diagenetic products of 2-methylbacteriohopanepolyols are second order biosignatures, that is bioindices of bioicons that refer to its content, life in the form of cyanobacteria.

\section{Bioindices}

“It happen'd one day about noon, going towards my boat, I was exceedingly surpris'd with the print of a man's naked foot on the shore, which was very plain to be seen in the sand: I stood like one thunder-struck, or as if I had seen an apparition" (Defoe 1719, 122). When Robinson Crusoe, shipwrecked and washed ashore on a seemingly uninhabited island, one day saw footprints in the sand, he knew that there was human life there - Friday. He came to the conclusion, not just because the footprint had a similarity (iconicity) with a human being, but because it had a causal link with the lifeform who made it, as an index of life. As a sign caused by its object, the index has an unintentional, causal link or contact with its content. Indexicality is, in this respect, 
meaning by proximity or contiguity. This contiguity does not necessarily have to be of real physical causality, it could consist of the mere perceiving of two objects together in space. Indices could also be related to factorality, when seeing something as a part of something else (Sonesson 1994). The interpretation of indices requires empirical knowledge of the recurrent connection between the sign and what it refers to. The perceptual world consists of a profuse amount of potential indexicality, even though we do not yet recognize these indices as signs with meaning. But the human mind constantly searches for and infers causalities and meaning in things perceived.

Bioindices are thus biosignatures that have a connection to their objects (the living organisms) by contiguity. In other words, the connection between the expression and the content is not based on similarity, but on indexicality, and is in semiotic terms something distinctly different than iconicity. Perhaps the clearest examples of bioindices are atmospheric, chemical biosignatures that refer to biological processes, such as the metabolism of living organisms. Homochirality and isotopic fractionation have been put forward as molecular evidence of metabolism. Biogenic minerals deposits of calcium carbonate, calcium phosphate, iron oxides, mangese, and sulphur could also be the products of microbial metabolic processes, and thus have this indexical relation, but are unfortunately very difficult to distinguish from minerals produced by mere abiotic processes. Fossils that record the behaviour or activity of an organism are another type of bioindices, in contrast to bioicons that has a similarity with the living thing. These artefacts of life, such as stromatolites formed by microbial mat communities, indicate a biotic origin. Other examples of bioindices that trace the behaviour of an organism are borings, burrows, footprints, etc. Again, the challenge here is to distinguish these bioindices from features that are a result of an abiotic process that mimic the biotic behaviour.

Remote sensing of planetary environments for habitability and biosignatures goes back to the nineteenth century. In his Cours de philosophie positive (1830-1842) the French positivist Auguste Comte said, concerning the celestial bodies, that "we will never by any means be able to study their chemical composition or their mineralogical structure" (Comte 1835, 2; Crowe 2008, 312). Some few decades later spectroscopy was developed. The turning point came with spectroscopic astronomy that gave a new powerful tool for searching extraterrestrial life. By analysing the spectra caused by the molecular absorption or emission at molecule-specific photon wavelengths, the spectroscopists could infer the chemical composition of the atmospheres of distant planets. The first spectroscopic observations aiming for detecting oxygen and water in the Martian atmosphere were made by the astronomers William Huggins and Jules Janssen in the 1860s. By assuming water as a necessary condition for life, and by linking planetary environmental conditions (presence of water vapour in the atmosphere and liquid water on the surface) with the possibility for life to emerge and subsist, they got a clue. A detection of water vapour in the atmosphere of a planet would then be a crucial indication that it might be life on its surface. In 1867, Janssen claimed that he had discovered the presence of water vapour in the Martian atmosphere, but in fact it was 
probably terrestrial signatures, already refuted by the American astronomer William Wallace Campbell in 1894 (Raulin Cerceau 2013).

There are hopes that we in the future will be able to observe the absorption or emission properties of atmospheres of small, rocky exoplanets (Seager 2014; Seager and Bains 2015). A first step in the search for biosignatures of exoplanets would be to study the temperature, size, mass, density, gravitation, and light conditions of the exoplanet. Next, to search for indications of atmosphere, liquid water, clouds, surface, plate tectonics, daily rotation, seasons, and weather. The third step would be to look for bioindices. For sure, we will not be able observe any surfaces of exoplanets with current technology, but we might soon be able to detect certain gases that we connect with life by remote sensing, even though the interpretation of the spectra involves a number of difficulties. In the future, the European Extremely Large Telescope (E-ELT) will make it possible to perform spectroscopic analysis of the faint light of an exoplanet, and might result in the first exoplanet atmospheric biosignatures. Our hopes rest on the assumption that certain gases in the atmosphere are produced by life (as we know from studies of our own terrestrial atmosphere), such as oxygen, ozone, methane, and carbon dioxide. Oxygen enrichment in the atmosphere could indicate the presence of oxygenic photosynthesis. Ozone, which is produced photochemically from biologically produced oxygen, could be another indication of biological activity. And methane could likewise be connected to the metabolism of living organisms. However, these gases could also be produced by abiological processes and exist without any biological activity. Some gases that are products of life on Earth, such as $\mathrm{CH}_{3} \mathrm{Cl}, \mathrm{CH}_{3} \mathrm{SH}, \mathrm{NO}_{2}, \mathrm{NH}_{3}$, would not be detected with current technology, due to low amounts, others, such as water and carbon dioxide have significant abiotic sources, and are less suitable as conclusive signatures of life. To conclude, the argument starts from the premises: $\left(\mathrm{P}_{1}\right)$ that life produces certain gases as a by-product of metabolism; $\left(\mathrm{P}_{2}\right)$ some of theses gases will accumulate in the atmosphere; and $\left(\mathrm{P}_{3}\right)$ that these gases show a unique spectrum. From these premises which we hold to be true and to be sufficient for detection - we conclude that life could, in theory, be detected through spectroscopy. But if $\mathrm{P}_{1}$ is false (there are metabolic processes that do not produce gases) or if $\mathrm{P}_{2}$ is false (these gases do not leak into the atmosphere) or we do not recognise the unique spectrum $\left(\mathrm{P}_{3}\right)$, we will fail.

It might rather be the combination of gases and the quantity of them, that closer reveals if there are life on the planet. Life leads to disequilibria, for example in respect to atmospheric chemical composition, entropy, etc. Earth-like atmospheric biosignatures disappear relatively quickly on a planet where life has ceased to exist. If there is a certain amount of a biosignature gas, it needs to have a continuous source. That gases in disequilibrium could be diagnostic for life was first suggested by Joshua Lederberg and James Lovelock in 1965 (Lederberg 1965; Lovelock 1965; Catling and Kasting 2007). And this atmospheric disequilibrium is detectable by spectroscopy, as in the case of spectral analysis of Earthshine (Arnold et al. 2002, 2008). The simultaneous presence of oxygen and methane indicates an atmospheric disequilibrium that could be assumed as a spectral evidence of life. The sustainable source of these gases, in this ratio, is life. The 
discovery of significant amounts of methane in the atmosphere of Mars then implies that there must exist a recent or current source, otherwise the methane would rather quickly disappear. The source could be geological activity and water in the subsurface or subsurface biology (Domagal-Goldman and Wright et al. 2016). As a recurrent theme in the search for life, the signs are ambiguous.

Another shipwrecked traveller in foreign territories, the ancient Greek philosopher Aristippus, was cast ashore on the Rhodian coast. But when he found geometrical figures in the sand, he became convinced that he had come to a land inhabited by civilized people (Vitruvius De architectura, 6.1). These Rhodian bioindices did not only indicate life, people, they indicated civilization. A certain class of bioindices could be categorized as technoindices, a second order index that indicate technology, which in its turn could indicate life. When analysing the spectra of exoplanets, one might find signs that do not have any known natural origin, such as industrial pollution, artificial molecules, for example pollutants like chlorofluorocarbons (CFCs), or other artificial traces of environmental disequilibrium that reverberates across the biosphere (Lin et al. 2014; Shostak 2015; Frank and Sullivan 2016), which we interpret as technoindices of advanced life forms that are able to artificially manipulate their environment. Monitoring the stars and planets in our galaxy we perchance come across signs of extraterrestrial civilizations revealed by their use of technology, for example radio emissions or other electromagnetic radiation leaking out from their planet voluntarily or involuntarily. Finding signs of technology does not necessarily lead to the conclusion that they originate from a civilization consisting of biological creatures, if one think of the highly hypothetic self-replicating "von Neumann machines" that replicate and disperse themselves without the dependence of biological creators.

The search for indices of life is a way of connecting phenomena around us, inferring that certain signs indicate a causal connection to their object and origin - life. This semiosis or meaning-making endeavour is however triadic, includes something more than expression and object, the biosignature and the living organism. As the astrophysicist Arthur Eddington (1920) touched upon: "We have found a strange footprint on the shores of the unknown. We have devised profound theories, one after another, to account for its origins. At last, we have succeeded in reconstructing the creature that made the footprint. And lo! It is our own" (Sullivan and Baross 2007, 6). It is ourselves, the interpreters that make this connection between expression and content. Searching for indices of life may reveal some knowledge about the living Universe wherein we live, but also an understanding of how we search for meaning in the seemingly chaotic world around us.

\section{Biosymbols}

August 15, 1977, the Big Ear radio telescope in Ohio received a very strong narrowband radio signal that lasted for 72 seconds. While reviewing the record date, the astronomer 
Jerry R. Ehman was stunned and wrote the comment "Wow!" on the computer printout. This anomaly has not been confirmed nor repeated (Kraus 1979). The first problem one faces in such a situation is to determine if it is a natural or an artificial signal, if one could rule out all known natural causes of the signal and conclude that it is an artificial signal caused by an intelligent civilization with advanced technology. This technosignature might indicate the existence of technology, as such a technoindex. The next problem that arises is to determine if it is something more than just an index of technology, but actually contains a message, a content that is meant to be communicated, deciphered, and understood by the receiver. Probably, we would not be satisfied with a mere conclusion that it is a technoindex, but that it contains symbolical information, that it is a technosymbol.

Searching for extraterrestrial intelligence by means of radio astronomy has been an exciting challenge ever since the start of Project Ozma in 1960 (Sagan 1973; Weston 1988; Tarter 2001; Drake 2011; Schuch 2011; Dunér 2015, 2017; Traphagan 2015; Vakoch and Dowd 2015; Cabrol 2016). The starting point of the argument is plausible. Electromagnetic leakage from Earth is detectable from outer space, and likewise, if an extraterrestrial intelligence is engaged in radio communication, we would be able, at least in theory, to detect its voluntary or involuntary broadcasts. The problem of interstellar communication lies not so much in the physical or technological constraints, even though they very much challenge our scientific and technological skills, but in the cognitive and semiotic problems that interstellar message decoding provoke (Dunér 2011, 2013, 2014).

Intelligence could be seen as an evolved mental gymnastics required to survive and reproduce within its specific environment. This includes the capability of representing activities and being able to make inner models of reality. By using symbols an intelligent creature could engage in abstract thinking detached from the environment, by which they can reason about things not existent; things that are not right in front of them, in a specific moment in time. Very effective tools for symbolizing thought are our communicational devices. According to the cognitive linguist John Taylor (2002), language can be understood as a set of resources that are available to the language user for the symbolization of thought, and for the communication of these symbolizations.

The problem with symbols is that they are conventional, or arbitrary, as Ferdinand de Saussure (1916) called them. Icons and indices are signs that have some nonarbitrary similarity or contiguity with the signified, in contrast to the symbols' completely arbitrary relation. For example the word "life" has no causal link to what it stands for, nor does it resemble what it signifies. There are no intrinsic relationship between the expression and content whatsoever. It is the interpreters (the ones that construct the message and the ones that decode them, respectively) that joins them together and establish the connection between the expression and the content. And the matching between the transmitters' and the receivers' interpretation of the symbols is by no means self-evident. We may figure out the reference of the signal, but will 
probably have severe problems understanding extraterrestrial symbols. It is not impossible to imagine that the aliens would have certain knowledge about their environment that in its content is similar to our own knowledge of mathematics, physics, and chemistry. But their expression of it would most likely be very different from ours. It is the message's expression rather than its content that becomes the difficulty for the interpreter. In symbols, there is a gap between the sign and meaning. Nothing in the physical appearance of the sign gives any clue to its object; they are instead linked by an arbitrary correlation. In fact, most attempts at interstellar message constructions violate this basic semiotic understanding of signs that distinguishes between expression and content. Symbols are detached representations and, as such, dependent on cultural and social interactions that create some specific regularities that have their origin in more or less stochastic habits, conventions, etc., of the species (Sonesson and Dunér 2016). Our communication and symbolization have evolved through an evolutionary and cultural-historical process here on Earth, and are thereby constrained by our human bodies, terrestrial environment, and the socio-cultural characteristics of our species. And likewise, a potential information transfer containing a symbolic message from an alien civilization would be constrained by the bio-cultural coevolution of the extraterrestrial intelligence that coded it.

\section{Conclusion}

The search for biosignatures is very much a semiotic problem. There seems to be something out there (the object), that makes or follows of a reaction (the expression), and this connection between the object and the expression is invented or discovered by an interpreter. In astrobiology one searches those expressions (the biosignatures) that could reveal the existence of the objects (life) that are the causes of these signatures. In this paper I have put forward a semiotic analysis of the semiosis of biosignatures. One of the fundamental insights of a semiotic approach is that the signrelation is triadic, it consists not only of a relation between content and expression - there is also an interpreter that establishes or makes the connection between them. In that respect the search for biosignatures goes on to a great extent in the human mind. The signrelation is not just out there, completely independent of interpreters that endow certain phenomena meaning and establish connections between things. An other basic semiotic interpretation of biosignatures is that they are not signs of a single, general kind. Biosignatures are in semiotic terms very diverse phenomena.

Following a Peircian division of three basic signrelations: icons, indices, and symbols, one could identify three kinds of biosignatures with their particularities and epistemological problems, which in my terms can be called, bioicons, bioindices, and biosymbols. Bioicons are biosignatures that share a similarity (in any sense modality) with its object, the living organism. Noticing the similarity is not sufficient, we need to know if this similarity lies not only in the eyes of the beholder, in our creative minds, or also in a physical correlation between the object and the expression: we need at theory 
that explains the similarity. Bioindices are biosignatures that have contiguity with their objects. The challenge is to recognize certain signs as indices of life, among a huge number of potential indices. Bioindices call for a profound empirical knowledge of recurrent connections between object and expression. Biosymbols, finally, are biosignatures where the connection between the expression and the object is a mere convention, habit, or rule. In contrast to icons and indices, the biosymbols are completely arbitrary, and depend on the socio-cultural context. This explains the challenges to decode and construct interstellar messages in order to transfer and aligning information and meaning. Even though the sender and the receiver have the same or similar knowledge about the object, the expression of it would most likely be very different due to different bio-cultural evolutionary histories.

The general epistemological problem of biosignatures is to recognize the signatures as meaningful, as signatures of life; that it is an expression that refers to a content (i.e. life). Second, one need to establish the connection between the expression and the object, the biosignature and the biological process that we call life, and arrive at a certain degree of certainty, and be able to rule out other explanations for the signatures that are not of biological nature. The central problem is about how we interpret signs, differ biosignatures from signatures that has no biological origin, how we are able to endow the world with meaning and identify signs of life among a profuse amount of signs in the universe.

\section{Bibliography}

Arnold L, Gillet S, Lardière O, Riaud P, Schneider J (2002) A test for the search for life on extrasolar planets: looking for the terrestrial vegetation signature on the earthshine spectrum. Astronomy and Astrophysics 392(1):231-237.

Arnold L (2008) Earthshine observation of vegetation and implication for life detection on other planets: a review of 2001-2006 works. Space Sci Rev 135:323-333.

Arrhenius S (1907) Panspermy: the transmission of life from star to star. Scientific American 196:196.

Berzelius JJ (1834) Ueber Meteorsteine. Ann Phys Chem 33:113-148.

Brasier MD, Green OR, Lindsay JF, McLoughlin N, Steele A, Stoakes C (2005) Critical testing of Earth's oldest putative fossil assemblage from the *3.5 Ga Apex chert, Chinaman Creek, Western Australia. Precambrian Res 140(1-2):55-102.

Cabrol NA (2016) Alien mindscapes: a perspective on the search for extraterrestrial intelligence. Astrobiology 16(9):1-16.

Catling D, Kasting JF (2007) Planetary atmospheres and life. In Planets and life: the emerging science of astrobiology, eds. Sullivan WT, Baross JA, 91-116. Cambridge: Cambridge University Press. 
Comte A (1835) Cours de philosophie positive: tome 2, contenant la philosophie astronomique et la philosophie de la physique. Paris: Bachelier.

Crowe MJ (1986) The extraterrestrial life debate 1750-1900: the idea of a plurality of worlds from Kant to Lowell. Cambridge: Cambridge University Press.

Crowe, MJ (2008) The extraterrestrial life debate, Antiquity to 1915: a source book. Notre Dame IN: University of Notre Dame.

Cutler A (2003) The seashell on the mountaintop: a story of science, sainthood and the humble genius who discovered a new history of the earth. New York: Dutton.

Defoe D (1719/2001) Robinson Crusoe, ed. Richetti J. New York: Penguin.

Domagal-Goldman SD, Wright KE, co-lead eds. (2016) The astrobiology primer v2.0. Astrobiology 16(8):561-653.

Drake F (2011) The Search for extra-terrestrial intelligence. Philosophical Transactions of the Royal Society A: Mathematical Physical and Engineering Sciences 369(1936):633-643.

Dunér D (2011) Cognitive foundations of interstellar communication. In Communication with extraterrestrial intelligence, ed. Vakoch DA, 449-467. Albany NY: State University of New York Press.

Dunér D (2013) Extraterrestrial life and the human mind. In The history and philosophy of astrobiology: perspectives on extraterrestrial life and the human mind, eds. Dunér D, Parthemore J, Persson E, Holmberg G, 7-31. Newcastle-upon-Tyne: Cambridge Scholars Publishing.

Dunér D (2014) Interstellar intersubjectivity: the significance of shared cognition for communication, empathy, and altruism in space. In Extraterrestrial altruism: evolution and ethics in the cosmos, ed. Vakoch DA, 139-165. Dordrecht: Springer.

Dunér D (2015) Length of time such civilizations release detectable signals into space, L, pre-1961. In The Drake equation: estimating the prevalence of extraterrestrial life through the ages, eds. Vakoch DA, Dowd MF, 241-269. Cambridge: Cambridge University Press.

Dunér D (2016) Science: the structure of scientific evolutions. In Human lifeworlds: The cognitive semiotics of cultural evolution, eds. Dunér D, Sonesson G, 229-266.

Pieterlen and Bern: Peter Lang.

Dunér D [2017] On the plausibility of intelligent life on other worlds: a cognitivesemiotic assessment of $f_{i} \cdot f_{c} \cdot L$. Environmental Humanities.

Dunér D, Sonesson G, eds. (2016) Human lifeworlds: the cognitive semiotics of cultural evolution. Pieterlen and Bern: Peter Lang. 
Eddington AS (1920) Space, time, and gravitation: an outline of the general relativity theory. Cambridge: Cambridge University Press.

Frank A, Sullivan III WT (2016) A new empirical constraint on the prevalence of technological species in the universe. Astrobiology 16(5):359-362.

Hegde S, Paulino-Lima I G, Kent R, Kaltenegger L, Rothschild L (2015) Surface biosignatures of exo-earths: remote detection of extraterrestrial life. Proceedings of the National Academy of Sciences, 112(13):3886-3891.

Hoffmeyer J, Favareau D (2008) Biosemiotics: an examination into the signs of life and the life of signs. Scranton: University of Scranton Press.

Horneck G, Klaus DM, Mancinelli RL (2010) Space microbiology. Microbiol Mol Biol Rev 74(1):121-156.

Horneck G et al (2016) AstRoMap European astrobiology roadmap. Astrobiology 16(3):201-243.

Kraus J (1979) We wait and wonder. Cosmic Search 1(3):31-34.

Lederberg J (1965) Signs of life: criterion system of exobiology. Nature 207:9-13.

Lin HW, Abad GG, Loeb A (2014) Detecting industrial pollutants in the atmospheres of Earth-like exoplanets. Astrophys J 792.Losch A, ed. (2017) What is life?: on earth and beyond. Cambridge: Cambridge University Press.

Lovelock JE (1965) A physical basis for life detection experiments. Nature 207:568-570.

McKay DS, Gibson EK Jr, Thomas-Keprta KL, Vali H, Romanek CS, Clemett S., Chillier XDF, Maechling CR, Zare RN (1996) Search for past life on Mars: possible relic biogenic activity in martian meteorite ALH84001. Science 273(5277):924-930.

Peirce CS (1932) Collected papers 2: Elements of logic. Cambridge MA: Belknap Press of Harvard University Press.

Peirce CS (1998) The basis of pragmaticism in the normative sciences. In The essential Peirce: selected philosophical writings. Vol. 2, 1893-1913. Bloomington IN: Indiana University Press.

Raulin Cerceau F (2013) Pioneering concepts of planetary habitability. In Astrobiology, history, and society: life beyond earth and the impact of discovery, ed. Vakoch DA, 115-129. Berlin \& Heidelberg: Springer.

Romanini V, Fernández E (2014) Peirce and biosemiotics: a guess at the riddle of life. New York: Springer.

Sagan C, ed. (1973) Communication with extraterrestrial intelligence. Cambridge MA: MIT Press. 
Saint-Gelais R (2014) Beyond linear B: the metasemiotic challenge of communication with extraterrestrial intelligence. In Archaeology, anthropology, and interstellar communication, ed. Vakoch DA, 78-93. Washington DC: NASA.

Saussure F de (1916) Cours de linguistique générale. Paris: Payot.

Schopf JW (1993) Microfossils of the Early Archean Apex chert: new evidence of the antiquity of life. Science 260(5108):640-646.

Schuch HP (2011) Project Ozma: the birth of observational SETI. In Searching for extraterrestrial intelligence: SETI past, present, and future, ed. Schuch HP, 13-18. Berlin: Springer.

Seager S (2014) The future of spectroscopic life detection on exoplanets. Proc Natl Acad Sci USA 111(35):12634-12640.

Seager S, Bains W (2015) The search for signs of life on exoplanets at the interface of chemistry and planetary science. Science Advances 1(2):1-11.

Shostak S (2015) Fraction of civilizations that develop a technology that releases detectable signs of their existence into space, $\mathrm{f}_{\mathrm{c}}, 1961$ to the present. In The Drake equation: estimating the prevalence of extraterrestrial life through the ages, eds. Vakoch DA, Dowd MF, 227-240. Cambridge: Cambridge University Press.

Sonesson G (1994) Prolegomena to the semiotic analysis of prehistoric visual displays. Semiotica 100(2-4):267-332.

Sonesson G (2007) From the meaning of embodiment to the embodiment of meaning. In Body, language and mind. Vol. 1: embodiment, eds. Zimke T, Zlatev J, Frank R. Berlin: Mouton.

Sonesson G (2009) The view from Husserl's lectern: considerations on the role of phenomenology in cognitive semiotics. Cybernetics and Human Knowing 16(34):107-148.

Sonesson G (2013) Preparations for discussing constructivism with a Martian (the second coming). In The history and philosophy of astrobiology: perspectives on the human mind and extraterrestrial life, eds. Dunér D, Parthemore J, Persson E, Holmberg G, 189-204. Newcastle-upon-Tyne: Cambridge Scholars Publishing.

Sonesson G, Dunér D (2016) The cognitive semiotics of cultural evolution. In Human lifeworlds: the cognitive semiotics of cultural evolution, eds. Dunér D, Sonesson G. Pieterlen and Bern: Peter Lang.

Sullivan WT, Baross JA, eds. (2007) Planets and life: the emerging science of astrobiology. Cambridge: Cambridge University Press.

Tarter J (2001) The search for extraterrestrial intelligence (SETI). Annual Review of Astronomy and Astrophysics 39:511-548. 
Taylor JR (2002) Cognitive grammar. Oxford: Oxford University Press.

Traphagan J (2015) Extraterrestrial intelligence and human imagination: SETI at the intersection of science, religion, and culture. Cham: Springer.

Vakoch DA (1998a) Constructing messages to extraterrestrials: an exosemiotic perspective. Acta Astronautica 42(10-12):697-704.

Vakoch DA (1998b) Signs of life beyond earth: a semiotic analysis of interstellar messages. Leonardo 31(4):313-319.

Vakoch DA, Dowd MF, eds. (2015) The Drake equation: estimating the prevalence of extraterrestrial life through the ages. Cambridge: Cambridge University Press.

Vitruvius (1934) On architecture: Books VI-X, ed. Granger F. Cambridge MA: Harvard University Press.

Westall F, Gobbi P, Gerneke D, Mazzotti G (1998) Ultrastructure in the carbonate globules of Martian meteorite ALH84001. In Exobiology: Matter, Energy, and Information in the Origin and Evolution of Life in the Universe, eds. Chela-Flores J, Raulin F, 245-250. Amsterdam: Kluwer.

Weston A (1988) Radio astronomy as epistemology: some philosophical reflections on the contemporary search for extraterrestrial intelligence. The Monist 71(1):88-100.

Wheeler W (2006) The Whole Creature: Complexity, Biosemiotics and the Evolution of Culture. London: Lawrence and Wishart.

Zlatev J (2012) Cognitive semiotics: an emerging field for the transdisciplinary study of meaning. Public Journal of Semiotics 4(1):2-24.

Zlatev J (2015) Cognitive semiotics. In International Handbook of Semiotics, ed. Trifonas P, 1043-1068. Berlin: Springer. 